\section{The transcephalic dc potential and scotopic critical flicker frequency}

\author{
HOWARD FRIEDMAN \\ Syracuse VA Hospital, Syracuse, N.Y. 13210
}

The relationship between the transcephalic DC potential (TCDC) and scotopic critical flicker frequency (CFF) was investigated in two groups of clinically normal male Ss. Comparisons of those Ss shifting in TCDC in a positive direction vs those shifting negatively and/or less positively were made. There was a replicable significant association between negative shifters prior to the scotopic CFF task and performance on that task.

In an attempt to elucidate an underlying mechanism through which external force fields, as magnetic radiation, could exert a biological effect, a primitive control system, the transcephalic DC potential (TCDC) has come under investigation (Becker, Bachman, \& Friedman, 1962; Cowen, 1965). ${ }^{1}$ Previous studies (Friedman, Becker, \& Bachman, 1967; Friedman \& Taub, 1969) dealing with a basic parameter of human psychomotor functioning, simple serial reaction time (RT), indicated that (1) temporary changes occurred in RT performance when low-level modulated magnetic fields were applied transversely across the cerebral area, and (2) a more positive TCDC shift over time was associated with relatively slower RT performance and more negatively shifting DC potential with relatively faster RT performance. The present study investigated the relationship of TCDC to a basic measure of discriminatory functioning, critical flicker frequency (CFF). Scotopic, rather than photopic, CFF was chosen, since Beischer et al (1967), in a study of the effects of a null magnetic field on human functioning, observed that out of a battery of physiological and psychological tests only peripheral CFF was significantly affected. Based on previous indications (Becker, Bachman, \& Friedman, 1962; Friedman, Becker, \& Bachman, 1962) that Ss shifting more negatively in TCDC tended to be more alert and vigilant than those shifting less negatively or in a positive direction, the following hypothesis was examined. It was anticipated that Ss shifting in a negative direction, or a relatively less positive direction, in TCDC would increase in discriminatory ability and exhibit, over trials, an elevation of the point of CFF; conversely, those shifting in TCDC in a relatively more positive direction would change, over trials, to a lower point of CFF.

\section{SUBJECTS}

The Ss were male white clinically normal volunteers between 18 and 26 years of age and without any significant visual defects.

\section{PROCEDURE}

Each of 67 Ss was placed in a sound- and lightproof chamber, with Beckman biopotential electrodes placed in the midline position on the forehead (recording electrode) and immediately above the occiput (reference electrode) and with ground electrode on the back of the hand. Head electrodes were kept in place by a rubberized bandage. An initial reading of this fronto-occipital potential was obtained with a Hewlett-Packard dc voltmeter which served as a check upon the continuously recording Beckman Type $R$ dynograph outside the sound chamber. The $S$ was dark-adapted for $30 \mathrm{~min}$ while listening to taped-in "show"-type popular music. After about $5 \mathrm{~min}$, a low-intensity red fixation light approximatley 16 in. from the $S$ became distinguishable to him. Just prior to the end of the dark adaptation, the $\mathrm{S}$ was asked to fixate the red light and, out of the corner of his eye, to note a flickering white light provided by the bulb of a Lafayette 1202-A flicker-fusion apparatus, which was 6 in. directly lateral to the red light. The intensity level of the flickering light was set so that it could be seen only by peripheral and never by direct vision. This was done to assure scotopic vision, and each $S$ was tested for this. With flicker rate adjusted by the $E$ outside of the chamber, the $S$ was then instructed to state when the flickering light appeared steady and when flicker reappeared. This was followed by determination of CFF threshold through a modified Method of Limits, using five ascending and five descending trials. The mean of an ascending and descending trial constituted the fusion point for that CFF trial. After the last trial, each $\mathrm{S}$ rather than photopic, vision. Electrodes were checked for drift and the very few Ss that exceeded $1 \mathrm{mV}$ of electrode drift during the was checked to assure use of scotopic, a p proximately $35-\mathrm{min}$ experimentation period were discarded. The same procedure was repeated on a second day with the same 67 Ss. The entire 2-day procedure was replicated exactly with another group of $68 \mathrm{Ss}$.

\section{RESULTS}

Four points were selected from which TCDC shift was measured: (1) first Dynograph reading, (2) 10th minute of dark adaptation, (3) $1 \mathrm{~min}$ before the task began, and (4) $1 \mathrm{~min}$ after task began. The differences between these points and all the possible following points $(10 \mathrm{~min}$ before task begins, 1 min before task begins, $1 \mathrm{~min}$ after task begins, halfway through task, $1 \mathrm{~min}$ before task ends, at end of task, and a final Dynograph reading) were considered as bases upon which to divide Ss into "positive" and "negative" shifters. In view of the small amount of change in CFF over the brief test period and since direction of change in CFF rather than magnitude is critical for the hypothesis of this study, the CFF for each $\mathrm{S}$ was only scored as higher or lower in flicker fusion point on Trial 5 as compared to Trial 1 . Thus, the data could be analyzed with a simple chi-square test $(\mathrm{df}=1)$. The general procedure was to divide the group of 67 Ss into those shifting most in a positive direction in TCDC vs those shifting negatively and/or less positively. This permitted division of Ss into 34 in one subgroup and 33 in the other, or very close thereto. The mean range of "positive" shifters was +8.5 to $+24.5 \mathrm{mV}$, and the mean range of "negative" shifters was +7.5 to $-21.0 \mathrm{mV}$. Each of the two subgroups, the "positive" shifters and the "negative" shifters, was then examined independently for the number of Ss decreasing in CFF over five trials vs those increasing or remaining unchanged. It turned out that only the first three points of origin for TCDC shift measurement could be used inasmuch as the changes from the point " $1 \mathrm{~min}$ after task began" to any other point was so slight as to preclude division of Ss into positive and negative shifters. Of the remaining three sets of criteria for division of the group, only the first, i.e., where CFF is measured from initial Dynograph reading to the various seven other points, gave significant results. Here, in each case, negative shifters provided significantly more Ss who were higher on CFF Trial 5 than on Trial 1.P values ranged from $<.05$ to $<.01$ in all cases. Positive shifters in no case achieved statistically significant levels. This finding did not appear on Day 2 for this group. Since the overall analysis represents an attempt to find a 
maximizing criterion out of a number of actually nonindependent criteria, this finding, without replication, could well be on a chance basis. Therefore, the entire experimental procedure was repeated with another group of $68 \mathrm{Ss}$. The findings were the same, with a mean range of +6.0 to $+26.5 \mathrm{mV}$ for the "positive" shifters and +5.0 to $-20.0 \mathrm{mV}$ for the "negative" ones. Again, only the first three points of origin for TCDC shift measurement could be used, only negative shifters from the first set of criteria gave statistically significant results, and the findings were not evident on Day 2. To determine whether the results were a possible consequence of negative shifters starting lower in CFF than positive shifters, the Trial 1 performances of the two subgroups were examined and showed no significant differences.

\section{DISCUSSION}

The results point to a replicable association between Ss shifting in TCDC prior to a task involving scotopic CFF and performance on that task. This relationship is limited in that it holds apparently only for those Ss shifting in a negative, or relatively negative, direction and only on first introduction to the task. Thus, it could be expected that Ss who were shifting negatively for $10-30 \mathrm{~min}$ would change subsequently in scotopic $\mathrm{CFF}$ in the direction of a higher point of fusion, i.e., increased discriminatory functioning. It is interesting to note that Friedman \& Taub (1969) observed that the highest levels of statistical significance in the relationship between TCDC and simple serial RT occurred when TCDC shift was measured during a period prior to the task or to a point $1 \mathrm{~min}$ into the task. Generally, the current finding is consonant with the notion of negatively shifting TCDC as related to the general state of alertness of the organism. It is in keeping with Rowland's (1968, pp. 63-68) discussion of the beahavioral (psychological) considerations associated with SP shifts. He points to the relation between "relative urgency" in observed behavior and significant SP shifts in animals. In human studies involving those SP shifts described as "contingent negative variations" (CNV), motivational or "interest" factors are apparently essential to elicit the CNV. Finally, the temporary nature of the phenomenon is in accord with Cowen's (1965) observation that the greatest impetus to a frontally negative shift is a "new and complex orientation in order to respond to a task."
REFERENCES

BECKER, R. O., BACHMAN , C. H., \& FRIEDMAN, $H$. The direct current control system: A link between environment and organism. New York State Journal of Medicine, 1962, 62, 1169-1176.

BEISCHER, E. D., MILLER, E. F., \& KNEPTON, J. C. JR Exposure of man to low intensity magnetic fields in a coil system. Bureau of Medicine \& Surgery, No. MR 005.04-0029.11, NASA Order R-37, October 3, 1967.

COWEN, M. A. The baseline transcephalic D.C. potential in normals. Journal of Psychiatric Research, 1965, 5, 307-315. FRIEDMAN, H., BECKER, R. O., \& BACHMAN, C. H. Direct current potentials in hypnoanalgesia. Archives of General Psychiatry, 1962, 7, 193-197.

FRIEDMAN, H., BECKER, R. O., \& BACHMAN, C. H. Effect of magnetic fields on reaction time. Nature, 1967 , $213,949-956$.

FRIEDMAN, H., \& TAUB, H. A. The transcephalic DC potential and reaction time performance. Psychophysiology, $1969,5,504-509$.

ROWLAND, V. Cortical steady potential (direct current potential) in reinforcement and learning. In $\mathbf{E}$. Stellar and J. M. Sprague (Eds.), Progress in physiological psychology. Vol. 2. New York: Academic Press, 1968.

\section{NOTE}

1. The TCDC may be subsumed under the general class of cortical steady potentials (SP), the literature of which has been reviewed by Rowland (1968). As described in the Procedure, recording technique, however, is considerably different from that used for typical SP recording. 